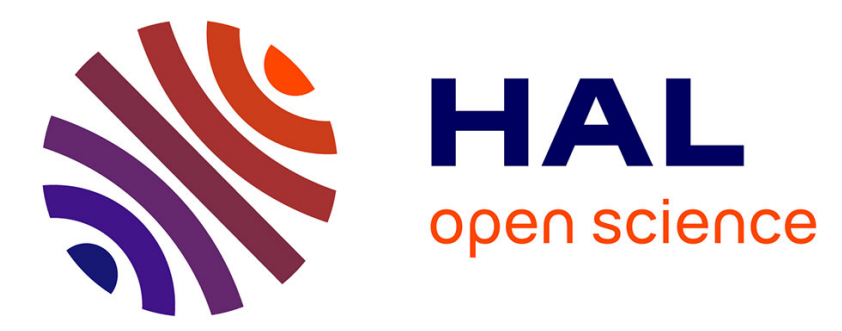

\title{
Attenuated effect of increased daylength on activity rhythm in the old mouse lemur, a non-human primate
}

Fabienne Aujard, Florence Cayetanot, Jérémy Terrien, Eus J.W. van Someren

\section{To cite this version:}

Fabienne Aujard, Florence Cayetanot, Jérémy Terrien, Eus J.W. van Someren. Attenuated effect of increased daylength on activity rhythm in the old mouse lemur, a non-human primate. Experimental Gerontology, 2007, 42 (11), pp.1079. 10.1016/j.exger.2007.08.007 . hal-00499026

\section{HAL Id: hal-00499026 https://hal.science/hal-00499026}

Submitted on 9 Jul 2010

HAL is a multi-disciplinary open access archive for the deposit and dissemination of scientific research documents, whether they are published or not. The documents may come from teaching and research institutions in France or abroad, or from public or private research centers.
L'archive ouverte pluridisciplinaire HAL, est destinée au dépôt et à la diffusion de documents scientifiques de niveau recherche, publiés ou non, émanant des établissements d'enseignement et de recherche français ou étrangers, des laboratoires publics ou privés. 


\section{Accepted Manuscript}

Attenuated effect of increased daylength on activity rhythm in the old mouse lemur, a non-human primate

Fabienne Aujard, Florence Cayetanot, Jérémy Terrien, Eus J.W. Van Someren

PII:

S0531-5565(07)00189-1

DOI:

10.1016/j.exger.2007.08.007

Reference:

EXG 8377

To appear in:

Experimental Gerontology

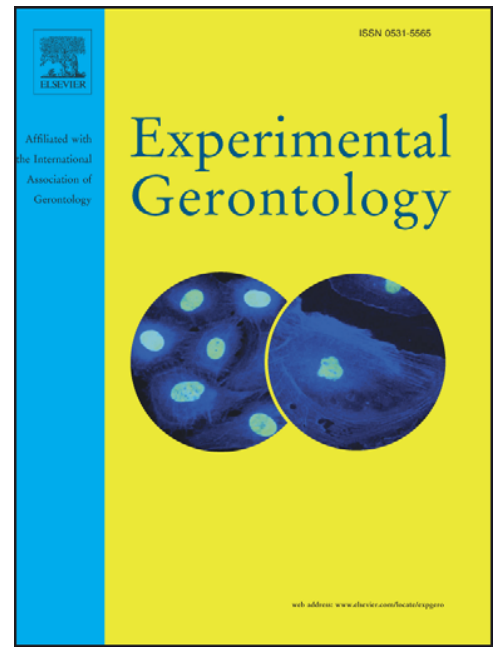

Received Date: $\quad 8$ June 2007

Revised Date: $\quad 16$ August 2007

Accepted Date: $\quad 21$ August 2007

Please cite this article as: Aujard, F., Cayetanot, F., Terrien, J., Van Someren, E.J.W., Attenuated effect of increased daylength on activity rhythm in the old mouse lemur, a non-human primate, Experimental Gerontology (2007), doi: 10.1016/j.exger.2007.08.007

This is a PDF file of an unedited manuscript that has been accepted for publication. As a service to our customers we are providing this early version of the manuscript. The manuscript will undergo copyediting, typesetting, and review of the resulting proof before it is published in its final form. Please note that during the production process errors may be discovered which could affect the content, and all legal disclaimers that apply to the journal pertain. 


\section{Attenuated effect of increased daylength on activity rhythm in the old mouse}

lemur, a non-human primate

\section{Fabienne Aujard ${ }^{a,{ }^{*}}$, Florence Cayetanot $^{a}$, Jérémy Terrien $^{a}$ and Eus J.W. Van Someren $^{\text {b,c }}$}

${ }^{a}$ Adaptive Mechanisms and Evolution, UMR CNRS/MNHN 7179, 1 avenue du petit Château, 91800 Brunoy, France

${ }^{b}$ Netherlands Institute for Neuroscience, Dept. Sleep \& Cognition, Meibergdreef 47, 1105 BA Amsterdam, The Netherlands

${ }^{c}$ VU University Medical Center, Depts. of Neurology, Clinical Neurophysiology and Medical Psychology, PO Box 7057, 1007 MB Amsterdam, The Netherlands

* Corresponding author:

Dr Fabienne Aujard

Adaptive Mechanisms and Evolution, UMR CNRS/MNHN 7179, 1 avenue du Petit Château, 91800 Brunoy, France.

Tel. +331604792 37 - Fax. +33160468118

E-mail: fabienne.aujard@wanadoo.fr

Running title: rhythms and daylength in an old primate

Keywords Aging; Primate; Circadian rhythm; Locomotor activity; Rhythm stability; Body temperature; Daylength; Season. 


\section{ABSTRACT}

Adaptation of physiological and behavioral functions to seasonal changes in daylength is of major relevance for optimal fitness and survival. Because aging is characterized by changes in biological rhythms, it may be hypothesized that old animals fall short of showing a full adaptation to prolonged changes in the duration of daily light exposure, as naturally occurring in relation to season in younger individuals. To test this hypothesis, we analyzed changes in the patterns of daily locomotor activity and body temperature rhythms of young and old mouse lemurs (Microcebus murinus, Primates) exposed to short and long daylengths. The effect of an increase in the duration of daily light exposure was attenuated in old animals, as compared to younger lemurs. Although some age-related differences in the locomotor activity rhythm could be seen under exposure to short daylength, they were predominant under long daylength. Some mechanisms allowing adaptation to changing day length thus seem to be impaired at old age. Changes in coupling of circadian oscillators to the light-dark cycle and disturbances in the physiological responses to change in light duration should be further investigated. 


\section{INTRODUCTION}

Aging is associated with changes in circadian rhythmicity of endocrine, metabolic and behavioral parameters in humans (Weinert, 2000; Van Someren and Riemersma - Van Der Lek, 2007). It has been demonstrated for various circadian rhythms that aging is characterized by a decrease in amplitude, a phase advance and an impaired resynchronization following abrupt phase shifts in the light-dark cycle. In humans, aging modifies the daily rhythm of restactivity. Aging is typically associated with (1) an increased fragmentation into shorter alternating periods of rest and activity; (2) an increased activity level during the major sleep period, (3) a decreased activity level during the major active period, and as a consequence (4) a decreased amplitude (Witting et al., 1990; Myers and Badia, 1995; Huang et al., 2002). The amplitude, pattern and phasing of the 24-hour profile of body temperature also changes with aging (Monk et al., 1995; Duffy et al., 1998; Gubin et al., 2006). However, some of the agerelated changes can be ameliorated by increasing the exposure to artificial bright light (Van Someren et al., 2002). Moreover, there is now some evidence that human rhythms are influenced by season through changes in the duration of daylength (Bronson, 2004), and it appears of interest to experimentally test the effect of daylength changes on the circadian rhythms of young and old subjects. However, changes in the duration of light exposure have rarely been taken into account in studies on circadian rhythms of old humans.

The effects of age on the circadian clock system have also been extensively studied in rodents (e.g. (Zee et al., 1992; Penev et al., 1997; Valentinuzzi et al., 1997; Mailloux et al., 1999; Zhang et al., 2000)), confirming rhythm disturbances such as an increased fragmentation and decreased amplitude of the daily locomotor activity rhythm, as well as a decreased precision in the onset of activity phase. Previous work in rodents and primates indicates that the sensitivity of the circadian timing system to short-term manipulation of light 
exposure may decrease with age (Zhang et al., 1996; Benloucif et al., 1997; Aujard et al., 2001). Taken together, these data suggest that age could have profound effects on the synchronization of circadian rhythms to changes in daylength. Rodent studies have shown that the effect of photoperiod on the temporal organization of daily rhythms is modulated by age (Scarbrough et al., 1997; Benstaali et al., 2002). In primates, the importance of daylength in the expression of activity patterns (Hill et al., 2004) and reproductive function (Chik et al., 1992) has been demonstrated in young adults only. It remains to investigate whether circadian rhythms responses to long-term changes in the duration of light exposure are comparable between old and younger primates.

The mouse lemur (Microcebus murinus, Primates) is a small nocturnal primate (body weight: 60 - 90 g) originating from Madagascar. This primate exhibits photoperiod-dependent seasonal and daily rhythms in most of its biological functions. Daily exposure to light for longer than $12 \mathrm{~h}$ promotes sustained behavioral activity, whereas daily exposure to light for less than $12 \mathrm{~h}$ reduces behavioral activity and leads to an increase in fat deposits (Perret, 1992). The life span of this species is about 8 - 10 years in captivity (Perret, 1997). Old animals show a decrease in amplitude of the seasonal variations in body mass, sexual hormones (Aujard and Perret, 1998), melatonin (Aujard et al., 2001) and DHEA-S (Perret and Aujard, 2005, 2006). Moreover, a recent study demonstrated that thermoregulation differed according to photoperiod and age in this species (Aujard et al., 2006), see comments in (Van Someren, 2007). Several of these studies indicate that daily and seasonal biological rhythms are altered in old mouse lemurs in ways that are remarkably similar to what is observed in human aging (Huang et al., 2002; Cayetanot et al., 2005): a decrease in amplitude of the locomotor activity level, an increased activity during the resting diurnal phase and an increase in fragmentation. For these and other reasons, the mouse lemur can be regarded as a model of primary importance for human aging (Bons et al., 2006). 
In the present study, we examined whether a prolonged exposure to an increased duration of daily light exposure would equally affect younger and older mouse lemurs with respect to their locomotor activity and body temperature rhythms. If a differential response to changes in the duration of daily light exposure exists, age-related differences in the expression of daily rhythms observed under one specific photoperiod may not surface under another photoperiod.

\section{METHODS}

\section{Animals}

All animals used in this study were born and kept in captivity in the laboratory breeding colony of the CNRS at Brunoy (MNHN, France, license approval N A91.114.1). General conditions of captivity were maintained constant with respect to ambient temperature (24 - 26 ${ }^{\circ} \mathrm{C}$ ) and relative humidity (55\%), food and water available ad libitum (including fresh fruits, a milky mixture and meal worms). In captivity, seasonal variations of physiological functions can be entrained by alternating 6-month periods of long daylength (14 h of light/day) and short daylength (10 h of light/day) under artificial light. Nine young male mouse lemurs (mean age: $2.5 \pm 0.5$ years, range: $1-4$ years) and 8 old male mouse lemurs (mean age: $7.3 \pm$ 0.8 years, range: 6 - 10 years) were studied.

Body mass of animals was higher in short daylength than in long daylength $\left(t\right.$-test, $t_{(16)}=$ 2.92, $P<0.01$ ). The body mass did not differ significantly between the 2 groups of mouse lemurs under each photoperiod (short days: young: $109 \pm 4$ g, old: $106 \pm 5$ g, $t$-test, $t(15)=$ 0.5, NS; long days: young: $93 \pm 9$ g, old: $91 \pm 4$ g, $t$-test, $t(15)=0.17$, NS). Thus, the age related differences observed in this study could not be attributed to differences in body mass. 
All experiments were carried out in accordance with the European Communities council Directive (86/609/EEC). All efforts were made to minimize animal suffering throughout the experiments.

\section{Procedures and lighting conditions}

Locomotor activity and core body temperature $\left(T_{c}\right)$ rhythms were recorded by telemetry (Dataquest LabPro System, Data Sciences, St Paul, Minnesota, USA) after implantation of a radio sensor-transmitter (TA10TA-F20 Data Sciences, St Paul, Minnesota, USA) in the visceral cavity under anesthesia (Valium 2mL/100g intra muscular, Imalgen 2mL/100g intra peritoneal). Mouse lemurs were housed individually in a cage containing a receiver board. Cages were placed in a chronobiological animal facility (Type A130-SP, Fisher Scientific Bioblock, Illkirch, France) with filtered air and controlled ambient temperature $\left(25 \pm 1^{\circ} \mathrm{C}\right)$. Each separated compartment was equipped with independent light-dark cycles, provided by cool fluorescent lamps (250 - 380 lux) during the light phase and with a dim red light $(0.002$ lux) during the dark phase. The lamps were placed on the side of the cage, at $10 \mathrm{~cm}$ from a wooden nest, where the animal could retire during the entire sleeping period, until it started its activity. All animals were tested after at least 1 month of exposure to a given photoperiod, a time lapse necessary for their complete physiological adaptation to the photoperiod (Perret, 1992). The recording period began at least 3 weeks after surgery. Locomotor activity and $T_{\underline{c}}$ were recorded simultaneously during 14 days after at least one month of exposure to a lightdark (LD) cycle of $10 \mathrm{~h}$ of light per day (short daylength), and then after at least one month of exposure to a LD cycle of $14 \mathrm{~h}$ of light per day (long daylength). The change in photoperiod was done by advancing the light onset by $4 \mathrm{~h}$, as previously used in synchronization studies (Perret and Aujard, 2001). 


\section{Data analysis}

Data were collected using a computerized data acquisition system (LabPro v.3.11, Data Sciences, St Paul, Minnesota, USA). $\mathrm{T}_{\mathrm{c}}$ (in ${ }^{\circ} \mathrm{C}$ ) was recorded for $10 \mathrm{~s}$ every 5 min and locomotor activity (in arbitrary units, AU) was recorded continuously. Actograms were performed using the Clocklab software (Actimetrics Inc., Evanston, IL). Quantitative characteristics of the locomotor activity rhythm were determined with non-parametric methods as previously described (Van Someren et al., 1999; Huang et al., 2002). Briefly, the following variables were calculated from the locomotor activity data. The interdaily stability quantifies the regularity of the timing of onset and offset of activity bouts and of the specific individual activity profile over days (increasing stability from 0 to 1 ). The intradaily variability quantifies the fragmentation of the period of rest and activity (increasing fragmentation from 0 to 2). L5 quantifies activity during the major sleep period as the average activity during the most restful 5-hour period of the activity profile. M10 similarly quantifies the average activity during the 10 most active hours. The amplitude of the locomotor activity rhythm was calculated as the difference between L5 and M10 values divided by their sum. Activity onset was defined as the first 6 successive bins where activity was greater than the mean locomotor activity during the light phase. $T_{C}$ data were analyzed for average nocturnal $\mathrm{T}_{\mathrm{C}}$ and both the level and timing of the daytime $\mathrm{T}_{\mathrm{c}}$ minimum (expressed in minutes prior to the time of lights on). When the activity onset precedes lights off, this phase advance is expressed by a positive value. Inversely, a phase delay is expressed by a negative value.

All values are expressed as mean \pm SEM and analyses were conducted using SYSTAT for Windows. Data were analyzed by two-way analysis of variance (ANOVA) on the effects of age, duration of light exposure and their interaction on repeated measures. One-way $\underline{\text { ANOVA was used to test the effect of duration of light exposure on activity onset in each age }}$ category. Differences in which $p<0.05$ were considered to be significant. 


\section{RESULTS}

\section{Effect of the duration of daily light exposure on the locomotor activity rhythm of young and old mouse lemurs}

Average 48h-profiles of locomotor activity and $\mathrm{T}_{\mathrm{c}}$ of young and old mouse lemurs exposed to either short or long daylength are represented in Fig. 1. Whatever their age category, all animals exhibited a daily rhythm of both parameters. In all cases, the nocturnal period corresponded to the active phase of the day, where animals exhibited the highest level of locomotor activity and the highest $\mathrm{T}_{\mathrm{c}}$ values. The profiles differed according to the duration of light exposure and age. Daylength-induced effects on the quantitative parameters of the daily locomotor activity rhythm in young and old mouse lemurs are represented in Fig. 2 and statistical results are indicated in Table 1 . We found a significant effect of the duration of light exposure, no overall effect of age but a significant age x daylength effect on interdaily stability, indicating that an increase in the duration of light exposure enhanced interdaily stability less in old than in young lemurs (Fig. 2A). There was a significant effect of the duration of light exposure and a significant effect of age on intradaily variability (Fig. 2B). Young animals exposed to long daylength exhibited a lower level of intradaily variability of the locomotor activity rhythm compared to young mouse lemurs exposed to short photoperiod. The significant age $\mathrm{x}$ daylength effect indicated that the increase in the duration of light exposure attenuated intradaily variability in young, but not in old animals.

The activity rhythm amplitude was also significantly affected by the duration of light exposure (Fig. 2C). There was a main effect of age and a significant age x daylength effect: an increase in the duration of light exposure enhanced the amplitude of the locomotor activity 
rhythm in young, but not in old animals. The activity level during the major sleep period (L5) was significantly affected by the duration of light exposure (Fig. 2D) as well. Due to high interindividual variability, the effect of age was only close to significance and no significant effect of age x daylength could be found. However, an increase in the duration of light exposure suppressed L5 in young mouse lemurs, but had no significant effect in old animals, which exhibited a high level of L5 whatever the duration of daily light exposure. The amount of activity during the major wakefulness period (M10) was significantly affected by the duration of light exposure, age and their interaction (Fig. 2E): when exposed to long daylength, young animals exhibited an increase of $43 \pm 7 \%$ relative to their M10 level when exposed to short daylength, while the average increase in the age group was only $26 \pm 7 \%$.

The onset phase of the major activity period always preceded lights off. There was no overall effect of the duration of daily light exposure on the onset of activity, but there was a significant effect of age (Fig. 2F). In all cases, animals started their activity period just shortly before lights off, except for old animals exposed to long daylength which exhibited a considerably earlier onset of their activity compared to their onset of activity under short daylength exposure. This effect of the duration of daily light exposure was significant in old animals, but not in younger ones (Table 2). Representative actograms of a young and an aged mouse lemurs exposed to long daylength are illustrated in Fig. 3.

\section{Effect of the duration of daily light exposure on the core body temperature rhythm of young and old mouse lemurs}

There was no age effect on the nocturnal level of $T_{c}$ or on the minimum $T_{c}$ value (Fig. 4A-B). A significant effect of the duration of daily light exposure was found for these two parameters that was due to an increase in average nocturnal $T_{c}$ and in the minimum of $T_{c}$ from short daylength to long daylength in both young and in old animals. 
There was a significant effect of age on time of occurrence of the minimum of $\mathrm{T}_{\mathrm{c}}$ (Fig. 4C). Whatever the duration of daily light exposure, the time of occurrence of the minimum of $\mathrm{T}_{\mathrm{c}}$ was delayed in old animals compared to younger ones. The minimum of $\mathrm{T}_{\mathrm{c}}$ occurred on average $174 \pm 25$ min after lights on in young and $280 \pm 23$ min after lights on in old animals, representing a delay of almost $2 \mathrm{~h}$ for old animals compared to younger ones.

\section{DISCUSSION}

An increase in the duration of daily light exposure had a more pronounced effect on the 24-h profile of locomotor activity rhythm in young than in old mouse lemurs. In old , as compared to short days, exposure to long days led to an increase in interdaily stability and activity level during the major period of wakefulness, yet in both cases less than the respective increases found in younger animals. Whether age affected the locomotor activity rhythm thus depended to a large extent on whether animals were observed during short days or long days: age-differences were much more pronounced during the period of longer daily light exposure. By contrast, no age difference could be detected in the response of the body temperature rhythm to changes in the duration of daily light exposure. Thus, although the activity rhythm response to an increase in the duration of daily light exposure was less in old animals, it was not completely absent, and even intact for the temperature rhythm response.

In young mouse lemurs, an increase in the duration of daily light exposure induced an increase in amplitude and activity during the major active period, and a decrease in activity during the major restful period, compared to exposure to short daylength. These effects do not match with the prediction of a potential masking effect of an increase in the duration of light exposure on the locomotor activity pattern of a nocturnal species, and rather suggest a full 
adaptation to each daylength. In aged animals, the effects of an increase in the duration of daily light exposure on locomotor activity levels were attenuated.

Like in young mouse lemurs, old animals exhibited a higher interdaily stability of their locomotor activity rhythm when exposed to longer days. A similar finding was observed in the elderly, in demented patients only (Van Someren et al., 1996). The patients showed a relatively higher interdaily stability during the summer. This indicates that there is at least some preservation of functional plasticity of the circadian timing system at high age (for review see (Van Someren et al., 2002)). Moreover, it is noteworthy that old animals started at higher interdaily stability during the shorter days than young animals did. A higher interdaily stability has also been observed in elderly humans and has been proposed to reflect a more rigid schedule of activity as an adaptive response to overcome a circadian system that is more easily disrupted (Monk et al., 1992; Carvalho-Bos et al., 2007; Van Someren and Riemersma - Van Der Lek, 2007). ().

Whatever the duration of the daily light exposure, young mouse lemurs were tightly entrained to the onset of lights off. In old animals, a long photoperiod was associated with an advanced onset of activity. Under short days, no difference could be seen between young and old mouse lemurs, since all animals started their activity close to the time of lights off. In young mouse lemurs maintained in free running condition (constant dim red light), the subjective day lasted $9.5 \pm 0.5 \mathrm{hr}$ (Perret and Aujard, 2001). It could thus be argued that the endogenous architecture of the circadian system would more readily adapt to a light period of 10 than of $14 \mathrm{hr}$. According to this contention, a 10-hr light period would require only an additional extension of $0.5 \mathrm{hr}$ on top of the endogenous $9.5 \mathrm{hr}$ of subjective day, while a $14-\mathrm{hr}$ light period would require an additional $4.5 \mathrm{hr}$ extension for an efficient synchronization. A reduced strength of lights on and lights off as potential zeitgebers has been demonstrated in old mice (Weinert and Weinert, 2003). Although this remains to be demonstrated in the 


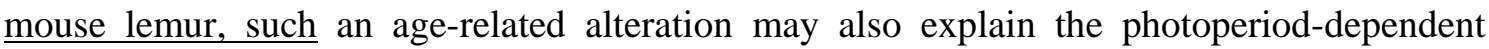
change in activity onset in old mouse lemurs.

In contrast to the activity rhythm response, the body temperature rhythm response to an increased duration of daily light exposure was preserved in old mouse lemur. The timing of minimal body temperature was delayed in old mouse lemurs compared to younger ones, irrespective of photoperiod. Of note, the delayed body temperature minimum in old mouse lemurs contrasts with the phase advance typical of old humans (Monk et al., 1995; Duffy et al., 1998). On the other hand, a delay in body temperature has been observed in demented elderly subjects (Harper et al., 2001), and Duffy et al. (Duffy et al., 1998) demonstrated that the body temperature nadir was actually delayed when expressed relative to the waking onset in the elderly. In mouse lemurs, the body temperature minimum was affected by photoperiod but not by age, while the timing of minimal body temperature changed according to age but not photoperiod. This corroborates the results of Benstaali et al. (Benstaali et al., 2002) in rats, showing that age and photoperiod acted independently on the daily rhythm of body temperature. The preservation of the body temperature rhythm response to daylength in old animals stands out as compared to the attenuated activity rhythm response, and also compared to previous findings in other rhythms. A decreased amplitude in seasonal variations of several other physiological parameters has also been demonstrated in old mouse lemurs, such as body weight (Aujard et al., 2001), behavioral thermoregulation (Aujard et al., 2006), testosterone (Aujard and Perret, 1998) and DHEA-S (Perret and Aujard, 2005).

In summary, although some age-related differences in the locomotor activity rhythm could be seen under exposure to short daylength, they were predominant under long daylength. Under short days, the patterns of old animals were close to those observed in young animals. Daylength effects on the rhythm parameters of young - but not old - animals led to the emergence of various age-related differences under exposure to long days. Some 
adaptive mechanisms allowing synchronization and entrainment to changing day length seem to be impaired with aging. It may be that at high age, a higher intensity of environmental light is required in order to obtain a full behavioral circadian response. It is also possible that, by increasing daylength, the coupling of individual circadian oscillators to the LD cycle or to other circadian parameters is modified. Changes in coupling of circadian oscillators to the light-dark cycle and disturbances in the physiological responses to change in light duration should be further investigated.

\section{ACKNOWLEDGEMENTS}

This work was supported by grants from the European Community QLK6-CT-200202258, ACI Neurosciences, Institute for Longevity, Foundation for Medical Research and (EvS) VIDI Innovation Grant 016.025.041, Netherlands Organization for Scientific Research (NWO), The Hague, The Netherlands.

\section{DISCLOSURE STATEMENT}

There is no conflict of interest concerning this work. Full agreement was obtain to conduct this work on the breeding colony of Brunoy (agreement \# A91.114.1). 


\section{REFERENCES}

Aujard, F., Perret, M., 1998. Age-related effects on reproductive function and sexual competition in the male prosimian primate, Microcebus murinus. Physiology and Behavior 64, 513-519.

Aujard, F., Dkhissi-Benyahya, O., Fournier, I., Claustrat, B., Schilling, A., Cooper, H.M., Perret, M., 2001. Artificially accelerated aging by shortened photoperiod alters early gene expression (Fos) in the suprachiasmatic nucleus and sulfatoxymelatonin excretion in a small primate, Microcebus murinus. Neuroscience 105, 403-412.

Aujard, F., Seguy, M., Terrien, J., Botalla, R., Blanc, S., Perret, M., 2006. Behavioral thermoregulation in a non human primate: Effects of age and photoperiod on temperature selection. Experimental Gerontology 41, 784-792.

Benloucif, S., Masana, M.I., Dubocovitch, M.L., 1997. Light-induced phase shifts of circadian activity rhythms and immediate early gene expression in the suprachiasmatic nucleus are attenuated in old C3H/HeN mice. Brain Research 747, 34-42.

Benstaali, C., Bogdan, A., Touitou, Y., 2002. Effect of a short photoperiod on circadian rhythms of body temperature and motor activity in old rats. Pflugers Archiv-European Journal of Physiology 444, 73-79.

Bons, N., Rieger, F., Prudhomme, D., Fisher, A., Krause, K.H., 2006. Microcebus murinus: a useful primate model for human cerebral aging and Alzheimer's disease? Genes Brain and Behavior 5, 120-130.

Bronson, E.H., 2004. Are humans seasonally photoperiodic? Journal of Biological Rhythms 19, 180-192. 
Carvalho-Bos, S.S., Riemersma-van der Lek, R.F., Waterhouse, J., Reilly, T., Van Someren, E.J.W., 2007. Strong association of the rest-activity rhythm with well-being in demented elderly women. American Journal of Geriatric Psychiatry 15, 92-100.

Cayetanot, F., Van Someren, E.J.W., Perret, M., Aujard, E., 2005. Shortened seasonal photoperiodic cycles accelerate aging of the diurnal and circadian locomotor activity rhythms in a primate. Journal of Biological Rhythms 20, 461-469.

Chik, C.L., Almeida, O.F.X., Libre, E.A., Booth, J.D., Renquist, D., Merriam, G.R., 1992. Photoperiod-Driven Changes in Reproductive Function in Male Rhesus-Monkeys. Journal of Clinical Endocrinology and Metabolism 74, 1068-1074.

Duffy, J.F., Dijk, D.J., Klerman, E.B., Czeisler, C.A., 1998. Later endogenous circadian temperature nadir relative to an earlier wake time in older people. American Journal of Physiology-Regulatory Integrative and Comparative Physiology 44, R1478-R1487. Gubin, D.G., Gubin, G.D., Waterhouse, J., Weinert, D., 2006. The circadian body temperature rhythm in the elderly: Effect of single daily melatonin dosing. Chronobiology International 23, 639-658.

Harper, D.G., Stopa, E.G., McKee, A.C., Satlin, A., Harlan, P.C., Goldstein, R., Volicer, L., 2001. Differential circadian rhythm disturbances in men with Alzheimer disease and frontotemporal degeneration. Archives of General Psychiatry 58, 353-60.

Hill, R.A., Barrett, L., Gaynor, D., Weingrill, T., Dixon, P., Payne, H., Henzi, S.P., 2004. Day length variation and seasonal analysis of behaviour. South African Journal of Wildlife Research 34, 39-44.

Huang, Y.L., Liu, R.Y., Wang, Q.S., Van Someren, E.J.W., Xu, H., Zhou, J.N., 2002. Ageassociated difference in circadian sleep-wake and rest-activity rhythms. Physiology and Behavior 76, 597-603. 
Mailloux, A., Benstaali, C., Bogdan, A., Auzeby, A., Touitou, Y., 1999. Body temperature and locomotor activity as marker rhythms of aging of the circadian system in rodents.

Experimental Gerontology 34, 733-740.

Monk, T.H., Reynolds, C.F., Machen, M.A., Kupfer, D.J., 1992. Daily Social Rhythms in the Elderly and Their Relation to Objectively Recorded Sleep. Sleep 15, 322-329.

Monk, T.H., Buysse, D.J., Reynolds, C.F., Kupfer, D.J., Houck, P.R., 1995. Circadian

Temperature Rhythms of Older-People. Experimental Gerontology 30, 455-474.

Myers, B.L., Badia, P., 1995. Changes in circadian rhythms and sleep quality with aging:

mechanisms and interventions. Neurosci Biobehav Rev 19, 553-71.

Penev, D.P., Zee, P.C., Turek, F.W., 1997. Quantitative analysis of the age-related

fragmentation of hamster 24-h activity rhythms. American Journal of Physiology 273, R2132R2137.

Perret, M., 1992. Environmental and social determinants of sexual function in the male lesser mouse lemur (Microcebus murinus). Folia Primatologica 59, 1-25.

Perret, M., 1997. Change in photoperiodic cycle affects life span in a prosimian primate (Microcebus murinus). Journal of BIological Rhythms 12, 136-145.

Perret, M., Aujard, F., 2001. Daily hypothermia and torpor in a tropical primate:

synchronization by 24-h light-dark cycle. American Journal of Physiology 281, R1925R1933.

Perret, M., Aujard, F., 2005. Aging and season affect plasma dehydroepiandrosterone sulfate (DHEA-S) levels in a primate. Experimental Gerontology 40, 582-587.

Perret, M., Aujard, F., 2006. Aging and biological rhythms in primates. M S-Medecine Sciences 22, 279-283.

Scarbrough, K., Losee-Olson, S., Wallen, E.P., Turek, F.W., 1997. Aging and photoperiod affect entrainment and quantitative aspects of locomotor behavior in Syrian hamsters. 
American Journal of Physiology-Regulatory Integrative and Comparative Physiology 41, R1219-R1225.

Valentinuzzi, V.S., Scarbrough, K., Takahashi, J.S., Turek, F.W., 1997. Effects of aging on the circadian rhythm of wheel-running activity in C57BL/6 mice. American Journal of Physiology-Regulatory Integrative and Comparative Physiology 42, R1957-R1964. Van Someren, E.J.W., Hagebeuk, E.E.O., Lijzenga, C., Scheltens, P., deRooij, S.E.A., Jonker, G., Pot, A.M., Mirmiran, M., Swaab, D.F., 1996. Circadian rest-activity rhythm disturbances in Alzheimer's disease. Biological Psychiatry 40, 259-270.

Van Someren, E.J.W., Swaab, D.F., Colenda, C.C., Cohen, W., McCall, W.V., Rosenquist, P.B., 1999. Bright light therapy: Improved sensitivity to its effects on rest-activity rhythms in Alzheimer patients by application of nonparametric methods. Chronobiology International 16, 505-518.

Van Someren, E.J.W., Riemersma, R.F., Swaab, D.F., 2002. Functional plasticity of the circadian timing system in old age: light exposure. Progress In Brain Research 138, 205-31. Van Someren, E.J.W., 2007. Thermoregulation and aging. American Journal of Physiology 292, R99-R102.

Van Someren, E.J.W., Riemersma-Van Der Lek, R.F., 2007. Live to the rhythm, slave to the rhythm. Sleep Medicine Review in press.

Weinert, D., 2000. Age-dependent changes of the circadian system. Chronobiology International 17, 261-283.

Weinert, D., Weinert, H., 2003. The relative Zeitgeber strength of lights-on and lights-off is changed in old mice.Chronobiology International 20, 405-416.

Witting, W., Kwa, I.H., Eikenlenboom, P., Mirmiran, M., Swaab, D.F., 1990. Alterations in the circadian rest-activity rhythm in aging and Alzheimer's disease. Biological Psychiatry 27, 563-572. 
Zee, P.C., Rosenberg, R.S., Turek, F.W., 1992. Effects of Aging on Entrainment and Rate of Resynchronization of Circadian Locomotor-Activity. American Journal of Physiology 263, R1099-R1103.

Zhang, B.L., Zannou, E., Sannajust, F., 2000. Effects of photoperiod reduction on rat circadian rhythms of BP, heart rate, and locomotor activity. American Journal of PhysiologyRegulatory Integrative and Comparative Physiology 279, R169-R178.

Zhang, Y., Kornhauser, J.M., Zee, P.C., Mayo, K.E., Takahashi, J.S., Turek, F.W., 1996.

Effects of aging on light-induced phase-shifting of circadian behavioral rhythms, fos expression and CREB phosphorylation in the hamster suprachiasmatic nucleus. Neuroscience 70, 951-61. 


\section{Figure captions}

Fig. 1. Average $( \pm S E M) 48$-h profiles of locomotor activity (A-B) and body temperature (CD) obtained from the 14 days of recording in young $(\mathrm{N}=9)$ and old mouse lemurs $(\mathrm{N}=8)$ exposed to either short daylength (LD 10/14, left panels) or long daylength (LD 14/10, right panels). Locomotor activity is expressed in arbitrary unit (AU). Light and dark phases are represented by white and black bars, respectively. Light-dark transitions are indicated by dashed lines.

Fig. 2. Differences in quantitative parameters of the locomotor activity rhythm (A: interdaily stability, B: intradaily variability, C: amplitude, D: activity during the 5 most restful hours (L5), E: activity during the 10 most active hours (M10), and F: activity onset) according to the duration of light exposure (short daylength LD 10/14 or long daylength LD 14/10) in young or old mouse lemurs. AU: arbitrary unit; ${ }^{*} P<0.05$; ${ }^{* *} P<0.01$; *** $P<0.001$.

Fig. 3. Representative actograms of the daily locomotor activity rhythm of a young and an old mouse lemurs exposed to LD 14:10. The red bar indicates the onset of lights off. Note the significant phase advance of the activity onset in the old animal.

Fig. 4. Differences in the daily body temperature $\left(T_{c}\right)$ rhythm parameters $\left(A\right.$ : nocturnal $T_{c}, B$ : minimum of $\mathrm{T}_{\mathrm{c}}$, and $\mathrm{C}$ : time of minimum of $\mathrm{T}_{\mathrm{c}}$ ) according to the duration of light exposure (short daylength LD 10/14 or long daylength LD 14/10) in young or old mouse lemurs. * $P<$ $0.05 ; * * * P<0.001$ 


\begin{tabular}{|c|c|c|c|c|c|c|}
\hline & \multicolumn{2}{|c|}{ Age effect } & \multicolumn{2}{|c|}{ Daylength effect } & \multicolumn{2}{|c|}{ Age $x$ daylength effect } \\
\hline & $\mathbf{F}$ & $p$ & $\mathbf{F}$ & $p$ & $\mathbf{F}$ & $p$ \\
\hline Interdaily stability & $F(1 ; 15)=0.5$ & NS & $F(1 ; 15)=92.7$ & $p<0.001$ & $F(1 ; 15)=7.8$ & $p<0.05$ \\
\hline Intradaily variability & $F(1 ; 15)=14.3$ & $p<0.01$ & $F(1 ; 15)=11.4$ & $p<0.01$ & $F(1 ; 15)=4.5$ & $p<0.05$ \\
\hline Amplitude & $F(1 ; 15)=9.2$ & $p<0.01$ & $F(1 ; 15)=30.6$ & $p<0.001$ & $F(1 ; 15)=39.8$ & $p<0.01$ \\
\hline L5 & $F(1 ; 15)=4.5$ & $p=0.05$ & $F(1 ; 15)=4.6$ & $p<0.05$ & $F(1 ; 15)=2.0$ & NS \\
\hline M10 & $F(1 ; 15)=10.7$ & $p<0.01$ & $F(1 ; 15)=67.3$ & $p<0.001$ & $F(1 ; 15)=4.9$ & $p<0.05$ \\
\hline Activity onset & $F(1 ; 15)=5.2$ & $p<0.05$ & $F(1 ; 15)=2.9$ & NS & $F(1 ; 15)=2.5$ & NS \\
\hline Nocturnal $T_{c}$ & $F(1 ; 15)=0.1$ & NS & $F(1 ; 15)=32.7$ & $p<0.001$ & $F(1 ; 15)=0.0$ & NS \\
\hline Minimum $T_{c}$ & $F(1 ; 15)=0.1$ & NS & $F(1 ; 15)=11.6$ & $p<0.01$ & $F(1 ; 15)=0.0$ & NS \\
\hline Time of minimum $\mathrm{T}_{\mathrm{c}}$ & $F(1 ; 15)=17.3$ & $p<0.01$ & $F(1 ; 15)=0.4$ & NS & $F(1 ; 15)=0.2$ & NS \\
\hline
\end{tabular}

Table 1. Two-way ANOVA results on the effect of age and daylength on the daily rhythms of locomotor activity and body temperature $\left(\mathrm{T}_{\mathrm{c}}\right)$ in young and old mouse lemurs exposed to either short (LD 10:14) or long photoperiod (LD 14:10). L5: activity during the major resting period of the day; M10: activity during the major active period of the day.

\begin{tabular}{ccccc}
\cline { 2 - 4 } & Photoperiod & Median & F & $p$ \\
\hline \multirow{2}{*}{ Young animals } & LD 10:14 & $-25 \mathrm{mn}$ & & \\
& LD 14:10 & $-10 \mathrm{mn}$ & & NS \\
\hline \multirow{2}{*}{ Old animals } & LD 10:14 & $-15 \mathrm{mn}$ & & \\
& LD 14:10 & $-50 \mathrm{mn}$ & $\mathrm{F}(1 ; 7)=5.98$ & $\mathrm{p}<0.05$ \\
\hline
\end{tabular}

Table 2. One-way ANOVA results on the effect of daylength on the onset of locomotor activity in each age category (young or old mouse lemurs), when exposed to either short (LD 10:14) or long photoperiod (LD 14:10). 

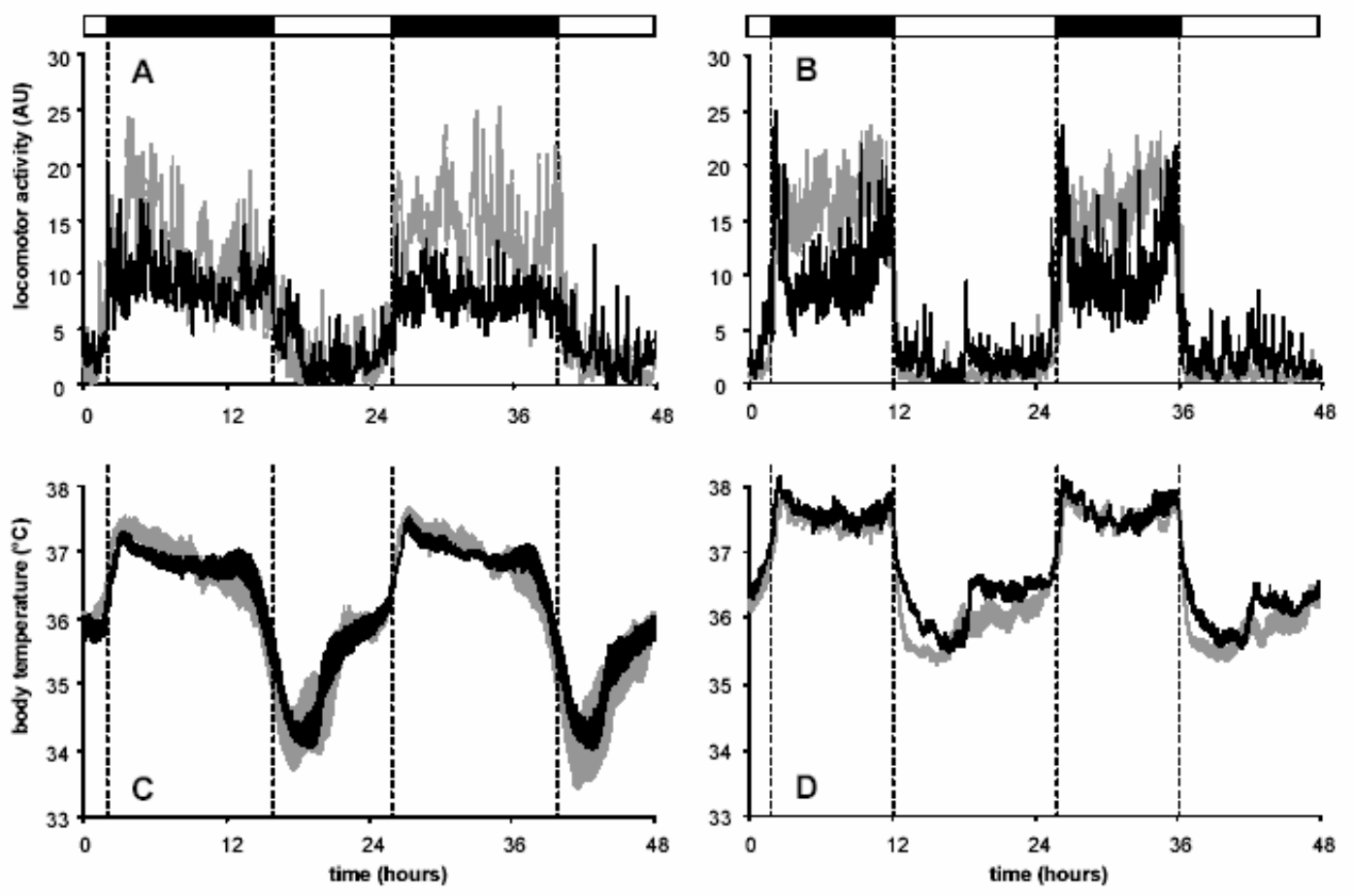

- old

Figure 1 

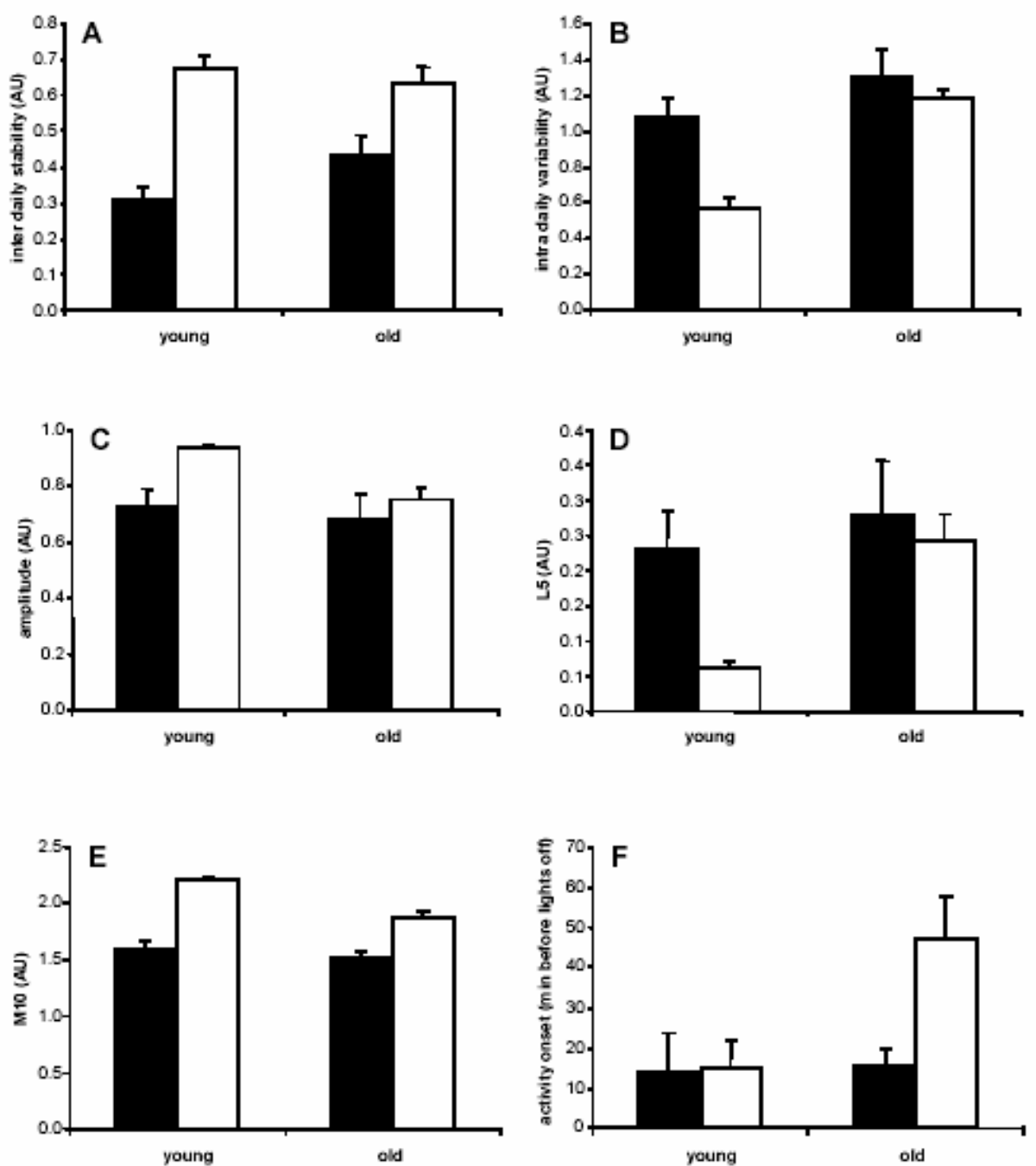

a short daylength

$\boldsymbol{\square}$ long daylength

Figure 2 


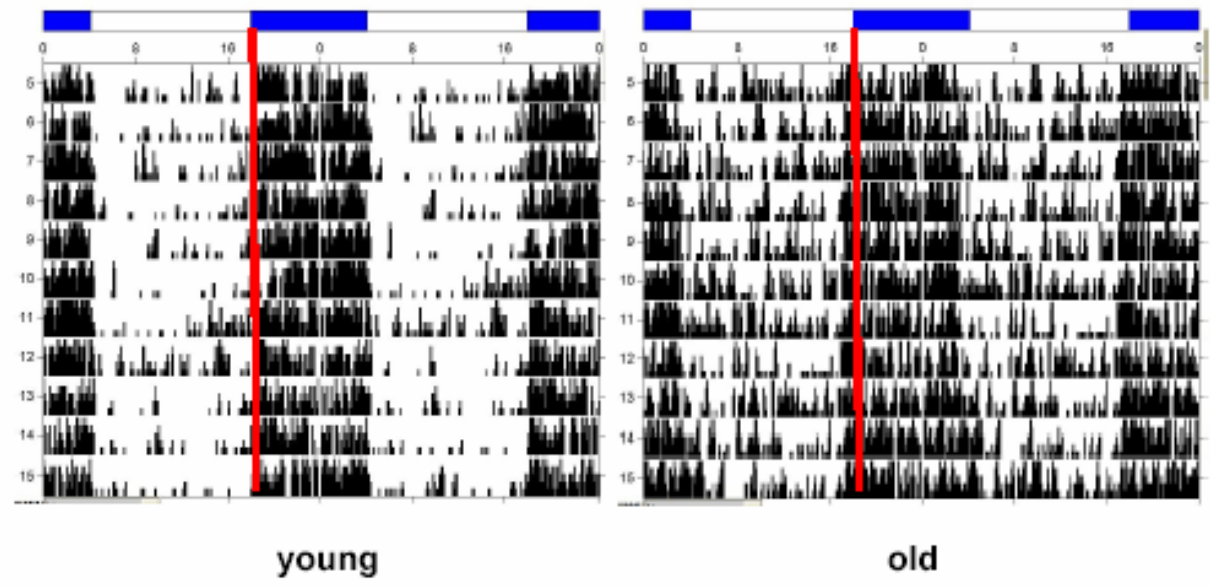

FIG.3 

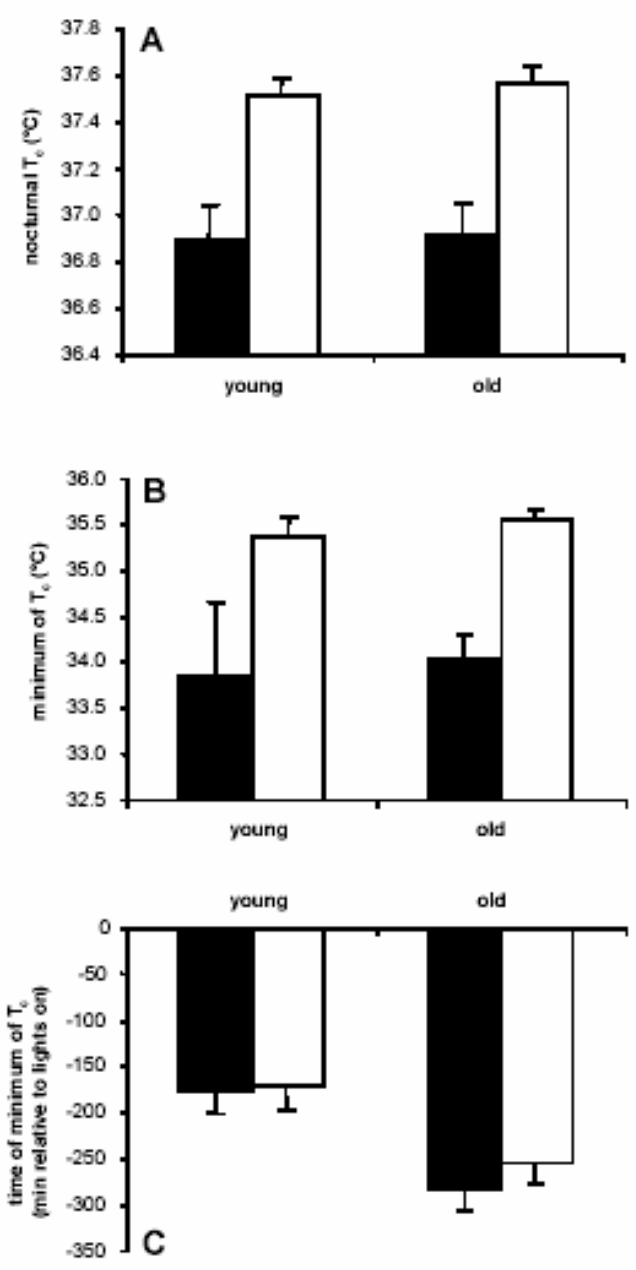

- short daylength

D long daylength

Figure 4 